\title{
Educación del derecho internacional en Bogotá: un primer diagnóstico a partir del análisis de los programas de clase y su relación con las epistemologías de no conocimiento***
}

\author{
The teaching of International Law \\ in Bogotá: A preliminary diagnosis, \\ departing from the analysis \\ of syllabuses and its relationship \\ with the epistemologies of not-knowing
}

RESUMEN

Este artículo presenta los resultados de un diagnóstico inicial realizado en 24 programas de cursos de derecho internacional (DI) de 10 universidades bogotanas para analizar y problematizar la educación del derecho internacional, a la luz de las epistemologías de la ignorancia (agnotología). Este primer estudio sobre el tema busca sentar las bases para discusiones futuras que lo complementen o contradigan y que resulten en, por ejemplo, trabajos que hagan propuestas para repensar los alcances de la enseñanza en derecho internacional en Bogotá.

El estudio preliminar muestra que la forma actual de educación del DI en Bogotá se caracteriza por una línea eurocéntrica clásica, no interdisciplinaria y donde la relación de la educación del DI con las problemáticas locales es limitada. El artículo muestra cómo la enseñanza del DI en Bogotá crea puntos ciegos epistemológicos o epistemologías de ignorancia. La creación de

Profesora asistente y directora de la Maestría en Derecho Internacional de la Facultad de Derecho, Universidad de los Andes (Bogotá, Colombia). Contacto: laurabr@gmail.com

** Profesor principal, Facultad de Jurisprudencia, Universidad del Rosario (Bogotá, Colombia).Contacto: enrique.prieto@urosario.edu.co

**** Recibido el 22 de enero de 2017, aprobado el 19 de abril de 2017.

Para citar el artículo: Betancur Restrepo, L. y Prieto-Ríos, E. Educación del derecho internacional en Bogotá: un primer diagnóstico a partir del análisis de los programas de clase y su relación con las epistemologías de no conocimiento. Derecho del Estado n. ${ }^{\circ}$ 39, Universidad Externado de Colombia, julio-diciembre de 2017, pp. 53-89. DOI: https://doi.org/10.18601/01229893.n39.04 
estas epistemologías de ignorancia limita la percepción y problematización para que los estudiantes y abogados, mediante la práctica de DI, puedan ver alternativas de conceptualización, reflexionando sobre los orígenes del DI, su relación con los proyectos coloniales e imperiales y su conexión con el contexto local.

PALABRAS CLAVE

Derecho internacional, educación legal, agnotología, epistemologías de ignorancia, Bogotá.

\section{ABSTRACT}

This paper presents the results of a preliminary empirical study analysing 24 syllabuses of International Law related subjects from 10 Universities in Bogotá. This empirical study is analysed using the theoretical framework of epistemologies of ignorance (agnotology). This preliminary and limited empirical study seeks to be the starting point for future discussions with colleagues in Colombia and in the region about the teaching and learning of IL in the region.

In pursuing this empirical research, the paper shows that the teaching of IL in Bogotá tent to take an orthodox and Eurocentric approach, not pursuing an interdisciplinary approach and not focusing on local problems. In this sense, the paper argues that the way how IL is taught in Bogotá creates epistemological blind spots, that we refer as epistemologies of ignorance. The creation of this epistemologies of ignorance limits the perception and problematisation that the students and IL lawyers may have in reflecting on the origins of the IL, its relationship with colonial and imperial projects and its relationship with the local context.

\section{KEYWORDS}

International Law, legal education, agnotology, epistemologies from the ignorance, Bogotá.

\section{SUMARIO}

Introducción. 1. Conceptualización de la agnotología en el contexto de la educación del DI en Bogotá. 2. ¿Para qué estudiar los programas de las clases de derecho internacional? 3. El caso de las universidades en Bogotá con registro de alta calidad. 4. Aspectos evaluados. 4.1. Objetivos y competencias esperadas. 4.2. Contenidos temáticos o programáticos. 4.3. Bibliografía. 5. Creación de vacíos y explicaciones posibles. Conclusiones. Referencias. Anexo. 


\section{INTRODUCCIÓN}

Este artículo presenta un primer piloto realizado en algunas universidades de Bogotá para analizar y problematizar la educación del derecho internacional (DI) a la luz de las epistemologías de la ignorancia. Con él queremos proponer un diagnóstico inicial realizado respecto de 24 programas de cursos de DI de 10 universidades bogotanas. Este diagnóstico es parte de un proyecto más ambicioso y extenso que busca estudiar la educación del DI en Latinoamérica ${ }^{1}$. Al estudiar estos programas buscamos observar si la forma actual de educación del DI puede generar epistemologías activas de falta de conocimiento (también llamadas por varios autores como epistemologías de ignorancia o agnotología) que sean resultado directo de procesos de invisibilización ${ }^{2}$.

Este es un tema que ha sido poco tratado, y lo ha sido solo de manera fragmentada, pero que vale la pena profundizar de forma más integral. Así, la educación del DI incluye aspectos que han sido materia de diversos estudios, algunos relacionados con el análisis de la educación jurídica ${ }^{3}$ y otros sobre la relación entre la educación jurídica y América Latina ${ }^{4}$. En cambio,

1 El proyecto general lo hemos denominado REDIAL (Repensar la Educación del Derecho Internacional en Latinoamérica). Este proyecto colectivo lo componemos los autores de este artículo junto con Paola Andrea Acosta (colombiana. Vinculada a la Universidad Externado de Colombia), Amaya Álves (chilena. Vinculada a la Universidad de Concepción), Fabia Fernades de Carvalho Veçoso (brasilera. Vinculada a la Universidad de Melbourne, Australia) y Jimena Sierra (colombiana. Vinculada a la Universidad del Rosario).

2 Véase Mendieta, E. The ethics of (not) knowing: The care of ethics and knowledge will come of its own accord. En Isasi-Díaz, A. M. y Mendieta, E. Decolonizing Epistemologies: Latina/o Theology and Philosophy. Fordham University Press, 2011, 252.

3 Véase, entre otros: Kennedy, D. ([1982] 1998) Legal Education as Training for Hierarchy. En D. Kairys (ed.) The Politics Of Law: A Progressive Critique (pp. 56-75), New York: Basic Books; Kennedy, D. Politicizing the classroom. Review of Law and Women Studies, 4, 1995, 81-88; Kennedy, D. Liberal Values in Legal Education, Nova L.J. 10, 1986, 603-617; Kennedy, D. The Political Significance of the Structure of the Law School Curriculum, 14 Seton Hall L. Rev. 14(1), 1983, 1-16; Kennedy, D. First Year Law Teaching as Political Action. En Law and Social Problems. 1(47), 1980, 47-58; De Sousa SANTOS, B. La Universidad en el siglo XXI. Para una reforma democrática y emancipadora de la Universidad. México: UNAM/CEIICH, 2005; McGee, J.; Guinot, M. y Connor, T. Rediscovering Law students as citizens critical thinking and the public value of legal education. Altern ative Law Journal.38(2), 2013, 1-8.

4 Véase, entre otros: LisTA, C. A. Los programas de "derecho y desarrollo" y la reforma judicial en América Latina, Anuario 10(7), 2007, 747-766; Lista, C. A. La construcción de la conciencia jurídica: los objetivos educativos y la formación del abogado, Anuario 5(3), 1999-2000, 381-404; PeÑa GonZÁLEZ, C. Characteristics and challenges of Latin American legal education. Paper presentedo a la Conference of International Legal Educators, Florencia, Italia, 2000, May 24-27; Pérez Perdomo, R. La formación jurídica en América Latina, tensiones e innovaciones en tiempos de la globalización. Bogotá: Universidad Externado de Colombia, 2006; Pérez Perdomo, R. Desafíos de la educación jurídica latinoamericana en tiempos de globalización. El Otro Derecho, La educación legal y la garantía de los derechos en América Latina. N. 38. Bogotá: ILSA - Instituto Latinoamericano para una Sociedad y un Derecho Alternativos, 2009; BRIGIDO, A. M. y LisTA, C. A. La enseñanza jurídica y el proceso de evaluación para la selección de funcionarios del Poder Judicial. Academia. Revista sobre Enseñanza del Derecho, 4(8), 2006, 
el tema de la educación del DI ha sido menos estudiado ${ }^{5}$ y no hay estudios profundos y actuales (o por lo menos no tenemos conocimiento de ellos) que analicen el tema de la educación del DI en América Latina, incluyendo específicamente a Bogotá. Aunque sin duda todos los estudios existentes ofrecen retroalimentaciones importantes para la reflexión que nos interesa, hay consideraciones propias del DI y del contexto local, nacional y regional que creemos importante abordar al analizar la educación de dicho derecho.

Por ejemplo, el DI a menudo es considerado como un derecho que solo es relevante cuando se trata de relaciones entre actores que interactúan a nivel internacional y que no concierne a la vida cotidiana de los ciudadanos. Sin embargo, esta percepción olvida que el DI también está presente en el día a día de operadores jurídicos y no jurídicos que impactan la cotidianidad local, nacional, regional e internacional (a través de decisiones judiciales nacionales e internacionales, decisiones de órganos administrativos, entre otras), haciendo que resulte cada vez más relevante la formación en esta área del derecho ${ }^{6}$. Pese a ello, la cuestión del qué y el cómo se enseña el DI en Colombia (incluyendo a Bogotá), y cuál es el impacto que ello tiene en el desarrollo de la vida nacional, no es objeto de un debate prioritario.

$\mathrm{Al}$ omitirse dicho debate, al evitar las preguntas sobre el tipo de información que se reproduce o el tipo de habilidades que se cultivan en quienes deciden formarse en esta área del conocimiento, se desaprovecha el potencial que tiene el DI, se exacerban los riesgos de su uso y abuso y se minimizan (o ignoran) sus impactos. Así, en la actualidad se puede constatar cómo el DI ha sido utilizado en el discurso de actores estatales y no estatales en Colombia para determinar las posibilidades, los deberes y los límites de lo que se puede acordar en materia de paz, sin que se analice o debata cómo se entiende y qué se entiende por este derecho. En estos casos vemos cómo el DI se presenta como un término unívoco y determinado, a pesar de que se usa muchas veces de forma contradictoria.

213-232; Fix-Fierro, H. y López Avellón, S. La educación jurídica en México. Un panorama general. En Pérez, R. y Torres. J. (eds.) La formación jurídica en América Latina, tensiones e innovaciones en tiempos de la globalización, Bogotá: Universidad Externado de Colombia, 2006, 143-184; Silva García, G. Prospectivas sobre la educación jurídica, 2006. En Pérez Perdomo R. y Cristina Torres J. (eds.) La formación jurídica en América Latina. Bogotá: Universidad Externado de Colombia; Montoya, J. The Current State of Legal Education Reform in Latin America: A Critical Appraisal. Journal of Legal Education. 9(4), 2010, 545-566; SALAMANCA RAmírez, F. A. Educación legal en Colombia. Análisis cuantitativo desde una perspectiva histórica. En García Villegas, M. (ed.) Los abogados en Colombia. Bogotá: Universidad Nacional de Colombia, caps. 3 y $5,2010$.

5 Sin embargo. Véase Kennedy, D. International Legal Education. Harvard International Law Journal, 26(2), 1985, 361-384.

6 Sobre la relación entre lo internacional y lo local. Véase EsLAVA, L. Local Space, Global Life. Cambridge: Cambridge University Press, 2016. 
Esta visión ha sido reiteradamente reevaluada y criticada por diferentes doctrinantes internacionalistas, incluyendo a la escuela crítica, y en particular por la corriente "Aproximaciones del Tercer Mundo al Derecho Internacional" (TWAIL, por sus siglas en inglés), quienes consideran que presentar el DI como único y homogéneo desconoce sus orígenes coloniales y las múltiples lecturas y usos que se pueden hacer del ordenamiento internacional, y que oculta los riesgos de manipulación del mismo ${ }^{7}$.

Consideramos que estas aproximaciones ayudan a develar algunos puntos ciegos presentes en la educación del DI y las repercusiones que de ellos se desprenden, incluyendo procesos activos de invisibilización importantes. Con este estudio esperamos contribuir a resaltar algunas de las conclusiones que son sensibles a este análisis crítico, aunque somos conscientes de que hay otras perspectivas posibles y otros puntos ciegos y sesgos presentes en esta propuesta.

En este orden de ideas, para evaluar el caso de las universidades en Bogotá creemos relevante tomar en consideración que en Colombia varias universidades han emprendido importantes reformas curriculares, que se ha fortalecido la profesionalización de la carrera académica en las facultades de derecho en las últimas décadas, que se han creado numerosos programas de doctorado, que los centros de investigación propios han crecido y que los sistemas de publicación y debate se están volviendo más rigurosos. Sumado a esto, muchos académicos colombianos y latinoamericanos se han formado y continúan formándose en diversas partes del mundo ${ }^{8}$, trayendo nuevas miradas y contenidos al debate nacional. Pero este proceso de fortalecimiento es aún reciente y sigue teniendo fuerte influencia extranjera, influencia que también ha cambiado.

En este sentido, es común destacar la tradicional influencia jurídica europea en el país tanto en la enseñanza (y producción) del derecho en general como del DI en particular. Precisamente, buena parte de los estudios "decoloniales" sobre el DI abordan y critican la "colonización” europea en materia jurídica en diferentes partes del mundo (incluyendo a Latinoamérica y Colombia). Adicionalmente, hoy en día la academia anglo-norteamericana es percibida como un modelo a seguir. Esto incluye que generalmente se tienda a adoptar su sistema de mediciones y rankings, sus métodos de investigación, su

7 Sobre los twaIl véase, entre otros: Singh Chimni, B. Third World Approaches to International Law: A Manifesto. International Community Law Review. Vol. 8, 2006, 3-27; ANGHIE, A. Imperialism, sovereignty, and the making of International Law. Cambridge University Press, 2007; Panuja, S. Decolonising International Law: Development, Economic Growth and the Politics of Universality. Cambridge University Press, 2011; GathiI, J. T. Twall: A Brief History of its Origins, its Decentralized Network, and a Tentative Bibliography. Trade, Law and Development. Vol. 3, n. ${ }^{\circ} 1,2011,26-64$.

8 Esquirol, J. L. Legal Latin Americanism, Yale Human Rights \& Development Law Journal, 2013, 145. 
idioma de comunicación ${ }^{9}$ e incluso sus aproximaciones epistemológicas e intereses conceptuales.

La información que compone el diagnóstico que acá presentamos nos permite, por un lado, comparar similitudes y diferencias entre los diferentes programas que estudiamos y, por otro lado, analizar si con el estudio del DI se generan epistemologías activas de falta de conocimiento. Eso a su vez aporta insumos para tener una mejor idea de los diferentes retos (institucionales, lingüísticos, sociopolíticos, etc.) a los que nos enfrentamos. En suma, este primer estudio sobre el tema busca sentar las bases de futuras discusiones que lo complementen o contradigan y que resulten en, por ejemplo, estudios que hagan propuestas para repensar los alcances de la enseñanza en derecho internacional en Bogotá, y que analicen si una relación concreta con lo local y/o regional en el estudio y educación del DI sería deseable o no.

Decidimos empezar por Bogotá por cuanto los autores somos bogotanos, hicimos parte importante de nuestra formación académica en Bogotá y actualmente trabajamos en universidades de esta ciudad; además, por las condiciones logísticas (de tiempo y económicas) que implicaría adelantar esta investigación en otras ciudades. De otra parte, el acceso a la información de universidades en Bogotá fue más fácil, y también nos permitió empezar por un campo de estudio que conocemos más profundamente, aunque sin duda impone sesgos ineludibles al presente trabajo.

Como explicaremos más adelante, decidimos tomar una muestra de programas de clases de DI pertenecientes a las facultades de derecho de universidades bogotanas que cuentan con registro de "alta calidad" del Consejo Nacional de Acreditación vinculado al Ministerio de Educación de Colombia ${ }^{10}$. Todos esos programas los analizamos según una encuesta realizada previamente que nos permitió elaborar una base de datos ${ }^{11}$. Parte de la información recogida se describe en este artículo. Esta información posteriormente la analizamos a la luz de los conceptos de las epistemologías de no conocimiento.

Las epistemologías de no conocimiento (epistemologías de ignorancia o agnotología) se refieren al estudio de la creación activa de lagunas. Vacíos o silencios en un saber específico; en este sentido no se trata de la ausencia sino de la creación activa de un vacío o un silencio ${ }^{12}$. Es muy importante resaltar la diferencia que existe entre la creación activa de ignorancia epistemológica y la ignorancia en su sentido y significado común. Este estudio no se centra

9 Como puede verse en este mismo artículo, en el que numerosas referencias están en inglés, incluso cuando se trata de autores de origen latinoamericano.

10 Sobre el Consejo Nacional da Acreditación. Véase: http://www.cna.gov.co/

11 Véase Anexo.

12 Mendieta. The ethics of (not) knowing, cit., 252; Prieto-Ríos, E. y Koram, K. Decolonising Epistemologies, Politicising Rights: An Interview with Eduardo Mendieta. 3 (1) Birkbeck Law Review 13, 2015. 
en la ignorancia en su sentido clásico, sino en la creación activa de silencios y vacíos en la educación del DI en Bogotá.

El esquema adoptado es el siguiente: comenzamos haciendo un breve marco conceptual sobre las epistemologías de la ignorancia y su relación con la educación del DI (1). Posteriormente pasamos a justificar por qué decidimos estudiar los programas de las clases de DI (2). Más adelante abordamos el análisis del estudio del caso, es decir, de los programas de clases de la selección de universidades bogotanas elegidas (3). Subsiguientemente se describen los aspectos evaluados (4). A partir de la información presentada, se reflexiona sobre la falta de una aproximación crítica en la educación del DI en las universidades en Bogotá y sobre la creación de vacíos y silencios en la educación del DI en Bogotá (5). Finalmente, proponemos unas conclusiones preliminares que buscan, más que dar por concluido el debate, hacer una invitación a continuarlo.

\section{CONCEPTUALIZACIÓN DE LA AGNOTOLOGÍA EN EL CONTEXTO DE LA EDUCACIÓN DEL DI EN BOGOTÁ}

La unión de las palabras 'epistemología' y 'no conocimiento' ubicadas de forma conjunta puede parecer contradictoria, y en una primera versión puede que con razón. La palabra 'epistemología' en su sentido restringido se entiende como los 'fundamentos y métodos del conocimiento científico' ${ }^{13}$, o también como el estudio de cómo el individuo conoce. De otra parte, en principio la expresión 'no conocimiento' (o ignorancia) es totalmente opuesta a conocer, es una falta de saber ${ }^{14}$. La falta de conocimiento es tradicionalmente asociada a falta de recursos, falta de tiempo o cualquier otra razón accidental que implica que esta falta de conocimiento puede ser remediada facilitando mayor acceso a recursos y herramientas, así como una mayor dedicación en la investigación del tema ${ }^{15}$.

Sin embargo, las epistemologías de no conocimiento o agnotología en la educación del DI en Bogotá, en el contexto de este artículo, no hacen referencia a la ausencia de conocimiento, ausencia que es resultado de situaciones accidentales de omisión que pueden ser resueltas mediante acciones dirigidas a solucionar la falta de conocimiento creada a partir de omisiones/ falencias; sino a una ausencia de conocimiento que es el resultado directo de una acción encaminada a crear procesos de invisibilización ${ }^{16}$. Lo anterior teniendo en cuenta que la falta de conocimiento también puede ser el resultado

13 Véase la definición en el Diccionario de la RAE. Disponible en: http://dle.rae. es/?id=Fy2OT7b visitado 15 de enero de 2016.

14 Véase ibíd.

15 Sullivan, S. y Tuana Race, N. Introduction. En Shannon Sullivan y Nancy (eds.). Tuana Race and Epistemologies of Ignorance (State University of New York Press 2007) 1.

16 Mendieta, The ethics of (not) knowing, cit., 252. 
de una acción, donde la ignorancia es activamente creada ${ }^{17}$. De esta forma, cuando nos referimos a epistemologías de no conocimiento (agnotologías) en la educación del DI, estamos haciendo referencia al análisis y problematización de la creación activa (acción) de silencios y vacíos en la educación del DI en Bogotá, que para el caso concreto de este artículo se hace a partir de un estudio empírico de los programas de DI de universidades en Bogotá.

Nuestro juicio inicial era que la enseñanza del DI en Bogotá se limita a una aproximación eurocéntrica clásica que (sin cuestionarlo) invisibiliza el origen colonial e imperial del DI, el ser facilitador de relaciones geopolíticas de poder y subordinación entre países; las particularidades de Colombia o Latinoamérica respecto del DI, o el uso de ciertas ramas del DI -como puede ser el DI de la inversión extranjera, que estructuralmente beneficia a unos $\operatorname{pocos}^{18}$, creando amnesias colectivas ${ }^{19}$. Este juicio creemos fue confirmado con el análisis de los programas de DI (ver sección 2 de este artículo). En este sentido consideramos que la creación de agnotología en la enseñanza del DI en Bogotá facilita la generación de amnesias colectivas sobre el pasado ${ }^{20}$.

Así, cuando nos referimos a la agnotología buscamos que sea claro y evidente que la enseñanza del DI en Bogotá está promoviendo que se dejen de lado otras aproximaciones posibles, incluyendo las aproximaciones críticas del DI que han permeado importantes (aunque minoritarios) centros académicos, no solo en Estados Unidos sino en varios países europeos y otras regiones del mundo. También aproximaciones críticas con enfoque de género, raza, o desde una perspectiva geopolítica en relaciones centro-periferia, como lo pueden ser las aproximaciones del Tercer Mundo al derecho internacional (TWAIL, por su nombre en inglés) que han convocado una interesante pluralidad de académicos en múltiples países del Sur y el Norte globales ${ }^{21}$.

Aunque las aproximaciones críticas al DI no son las únicas ni las más importantes, consideramos que contienen una perspectiva que invita a cuestionar supuestos dados del DI como disciplina, tales como su historia (generalmente relacionada con un pasado colonial), su objetividad-neutralidad y los sujetos de la disciplina. También nos invita a adaptar su estudio y énfasis a necesidades

17 Véase Diccionario de la RAE, cit.

18 Véase Miles, K. International Investment Law: Origins, Imperialism and Conceptualizing the Environment. Colorado Journal of International Environmental Law and Policy 1, 2010, 21(1); Prieto-Ríos, E. Neoliberal Market Rationality: The Driver of International Investment Law. Birkbeck Law Review 55, 3 (1), 2015.

19 Sullivan y Racel. Introduction, cit., 3.

20 Sullivan y Racel. Introduction, cit., 3.

21 Véase el mapa de las diferentes disciplinas del DI, incluyendo la Escuela Crítica y sus escuelas o movimientos relacionados, hecho por David Kennedy, o bien el índice bibliográfico sobre la teoría jurídica crítica en DI hecha por Jason Beckett. Kennedy, D. The disciplines of International Law and Policy. Leiden Journal of International Law 12 (1) 9-133, 1999; BECKETT, J. (2012) Critical International Legal Theory, Oxford Bibliographies Online: http://oxfordindex. oup.com/view/10.1093/obo/9780199796953-0007 
más locales y regionales, pudiendo acercarla a realidades como la colombiana, tener en cuenta su pasado colonial y su condición de país periférico en la actualidad. Ahora bien, no siempre seguir o incorporar reflexiones y materiales de escuelas críticas implica cuestionar los supuestos dados del DI, ni hacer énfasis en lo regional o local. Si bien su metodología y aportes teóricos invitan a explorar cuestiones diferentes que incluyen tomarse más en serio el contexto (global, local y regional) y cuestionar supuestos que son percibidos como dados o naturales, etc., en ocasiones pueden ser percibidos como metodologías y aportes importados que buscan reemplazar otros más "anticuados" (formalistas, tradicionales) y que se presentan como un nuevo modelo "verdadero", y hasta como una nueva forma de colonización epistemológica.

La creación de epistemologías de ignorancia en la enseñanza del DI en Bogotá está relacionada con el contexto y la estructura donde se encuentran los sujetos que generan los vacíos y silencios ${ }^{22}$, en este caso, nosotros, profesores de DI en Bogotá. La agnotología genera distorsiones respecto de la historia, construcción y fines del $\mathrm{DI}^{23}$, afectando la posibilidad de que los estudiantes de DI puedan ver alternativas de conceptualización del DI ${ }^{24}$. Al mismo tiempo, la generación de estos vacíos y silencios da lugar a puntos ciegos que hacen que los profesores de DI tengan un papel activo en la perpetuación de la falta de conocimiento, perpetuando desigualdades epistemológicas, sociales y económicas derivadas de procesos coloniales ${ }^{25}$.

Sin duda, la agnotología puede evidenciarse tanto en la creación como en la transmisión y aplicación del conocimiento en el DI. En este sentido, el lector puede asumir, al analizar la forma como se estudia y enseña del DI en Bogotá (p. ej., al estudiar la bibliografía y temas estudiados), que el interés inicial recae solamente en la transmisión del conocimiento. Sin embargo, al privilegiar el análisis de la transmisión no queremos dejar de lado la posible influencia que las epistemologías de ignorancia tienen en la creación y en la aplicación del DI. Lo anterior teniendo en cuenta que, en nuestra opinión, la creación, la transmisión y la aplicación conforman una relación circular. Es decir, la historia y la aplicación están marcadas por procesos de invisibilización activa de un pasado colonial e imperial, limitadas a un monopolio

22 Martín Alcoff, L. Epistemologies of Ignorance Three Types. En Sullivan y Racel (eds.). Race and Epistemologies of Ignorance, cit., 43.

23 Sullivan y Racel. Introduction, cit., 3.

24 BECKER LORCA, A. International Law in Latin America or Latin American International Law? Rise, Fall, and Retrieval of a Tradition of Legal Thinking and Political Imagination, 47(1) Harvard International Law Journal 283, 2006.

25 Koran y Prieto-Ríos. Interview with Eduardo Mendieta, cit.; Aníbal Quijano, 'Colonialidad del Poder, Eurocentrismo y America Latina. En LANDER, E. (ed.), La colonialidad del saber: eurocentrismo y ciencias sociales. Perspectivas latinoamericanas. FACES/UCV, UNESCO, IESALC, 2000, 311. 
normativo de Occidente y donde la aplicación ha garantizando la continuación en las relaciones de poder y en la subordinación entre Estados del centro y de la periferia. En este sentido, la transmisión del DI permite evidenciar la agnotología no solo en relación con su transmisión, sino también con su creación y aplicación.

En este sentido, consideramos que es importante analizar si es posible detectar en los programas de clases de DI una línea de educación tradicional eurocéntrica, que invisibiliza y crea vacíos en aspectos importantes, como pueden ser: la relación entre los proyectos coloniales e imperiales y el DI; la existencia de relaciones epistemológicas, regulatorias y económicas entre el centro y la periferia; si la escuela angloamericana ha efectivamente ganado espacios en la academia del DI bogotana; si esto hace que se afecte su eurocentrismo o no; si las aproximaciones críticas al DI han ganado espacios importantes en la educación del DI en Bogotá; si se están generado epistemologías activas de falta de conocimiento; entre otros.

Consideramos importante hacer dos precisiones: por un lado, que aunque una aplicación en la forma como se enseña el DI en Bogotá puede permitir una mejor lectura y apreciación por parte de los estudiantes que puede repercutir en la creación y la aplicación del DI en y desde la periferia, también es claro que una enseñanza solamente desde una óptica crítica puede crear a su vez otras formas de epistemologías de la ignorancia. De otro lado, que el propósito de este texto es el de servir como un primer diagnóstico, que pueda ser útil como instrumento para crear espacios de discusión con pares con el objeto de hacer nuevas propuestas apropiadas para Bogotá, las cuales pueden resultar contrarias a las perspectivas teóricas presentadas en este artículo.

\section{2. ¿PARA QUÉ ESTUDIAR LOS PROGRAMAS DE LAS CLASES DE DERECHO INTERNACIONAL?}

La pregunta que puede surgir al respecto es: ¿por qué justamente enfocarse en el DI? Como ya hemos dicho, hay varios estudios sobre la enseñanza del derecho en Latinoamérica ${ }^{26}$. Sin embargo, estas investigaciones se han concentrado principalmente en el análisis de los planes de estudio y no en los contenidos de los programas de áreas específicas, tales como el DI. Ahora bien, el DI tiene unas particularidades propias que creemos vale la pena considerar.

Los objetivos y las funciones del DI pueden variar dependiendo de la posición de las personas que lo estudien o utilicen. Sin embargo, en términos generales el DI tiene una importancia particular en el ámbito internacional, porque se presenta como el conjunto de reglas que regulan las relaciones entre sujetos de derecho internacional y que permite la realización de sus intereses y sus valores, lo cual contribuye a mantener unos estándares mínimos en las

Véase supra, nota 4. 
relaciones (económicas, políticas, diplomáticas, etc.) entre los Estados a nivel mundial ${ }^{27}$. De otra parte, cada día es más evidente que la interpretación y aplicación del derecho interno está estrechamente relacionada con el $\mathrm{DI}^{28}$, lo cual implica que el DI está presente en el día a día de operadores jurídicos y no jurídicos que impactan la cotidianidad local, nacional y regional, haciendo que resulte cada vez más relevante la formación en esta área del derecho ${ }^{29}$.

Adicionalmente, el DI es un ordenamiento jurídico con pretensiones de aplicación global y de estandarización que busca llegar a una diversidad de actores, y que es presentado como único, homogéneo y objetivo. De igual forma, a menudo se minimizan los efectos y particularidades de este derecho en el ámbito local y se le presenta como algo abstracto, que solo interesa a las relaciones interestatales.

Por todo lo anterior, consideramos relevante hacer un aporte a los estudios sobre la enseñanza del DI en un ámbito local concreto: Bogotá, comenzando por un diagnóstico inicial que nos permita mirar con más detenimiento cuál es el estado actual de la educación del DI en la ciudad, así como los retos y dificultades de esta actividad a la hora de servirse de ella como herramienta para fortalecer la educación jurídica en el país y la posible generación activa de epistemología de falta de conocimiento. A partir de este diagnóstico inicial, quisiéramos lograr, en el futuro, delinear una propuesta para potenciar los alcances de la educación en DI en Bogotá y Colombia que pueda servir como punto de partida para discusiones con otros pares, como base para estudios más amplios en el país y para adelantar estudios comparados posteriores en el resto del país y con otros países de la región.

Para empezar este diagnóstico, decidimos comenzar por analizar los programas de cursos o currículos (syllabus) de DI dictados a nivel de pregrado en universidades acreditadas en Bogotá. Somos conscientes de las muchas limitaciones y sesgos que tiene esta elección. Sabemos que la información que se pueda obtener de los programas es limitada, que los currículos son muy diversos entre sí y que no todos proporcionan la misma información. También somos conscientes de que el programa presentado por un profesor no da cuenta de otros posibles currículos (ocultos o silenciados) que muchas veces juegan un rol más destacado en la enseñanza de la materia del que se percibe del programa presentado y/o planeado.

Adicionalmente, hay desafíos futuros importantes, como determinar si los resultados entre universidades, ciudades y países son comparables y hasta qué punto. Por ejemplo, en este caso, es necesario tener en cuenta las

27 Kunz, J. L. A Plea for More Study of International Law in American Law Schools The American Journal of International Law 624, 1946, 40 (3).

28 Ibíd.

29 Sobre la relación entre lo internacional y lo local. Véase EsLaVA, L. Local Space, Global Life. Cambridge: Cambridge University Press, 2016. 
complejidades propias de hacer un estudio de este tipo en Colombia, y más aún en su ciudad capital, teniendo en cuenta que es un país profundamente desigual y que eso se refleja en el tipo de educación que se obtiene en sus universidades. Los estándares, influencias y posibilidades no son los mismos entre las ciudades grandes y pequeñas y entre las universidades de una misma ciudad. Por último, hay límites impuestos por nuestros propios sesgos como estudiantes de pregrado de esas universidades de élite bogotanas, que contamos con estudios internacionales y que actualmente trabajamos en esos centros universitarios estudiados.

A pesar de los retos, dificultades y cuestionamientos que implica una muestra pequeña de análisis de programas, limitada a Bogotá, consideramos que es un buen punto de partida como diagnóstico inicial que puede complementarse más adelante. Por último, adelantar un diagnóstico de la educación del DI y de los silencios y vacíos activos que los profesores creamos, es un primer paso para fortalecer una red de académicos y académicas internacionalistas en los niveles local, nacional y regional interesados en el reto de la educación del DI. Esto también nos ayudará a establecer un diálogo entre pares, respetuoso pero crítico, sobre la situación actual y las preguntas que podamos formular respecto del ejercicio, incluyendo lo que parecen ser las principales debilidades y fortalezas en la forma en que enseñamos y aprendemos el DI.

El caso de las universidades en Bogotá con registro de alta calidad

Como lo mencionábamos en la anterior sección, decidimos empezar el diagnóstico con una muestra de universidades de Bogotáa ${ }^{30}$, para lo cual se hizo una recolección de programas de cursos relacionados con DI, dictados a nivel de pregrado. Se seleccionaron las universidades de Bogotá cuyo programa de derecho cuenta con registro de "alta calidad" del Consejo Nacional de Acreditación ${ }^{31}$. De esta lista conformada por 13 universidades logramos obtener programas de 10 de ellas ${ }^{32}$. Se analizaron un total de 24 programas de clases de DI. De cada una de estas universidades se tuvieron en cuenta un mínimo de 1 programa y un máximo de 3 , todos relacionados con asignaturas dictadas a nivel de pregrado, sobre DI. Todos los programas recolectados fueron procesados siguiendo un modelo de encuesta realizado previamente y

30 Si bien la Universidad de la Sabana técnicamente no se encuentra ubicada en Bogotá D.C., sino en el municipio aledaño de Chía, sus programas pueden considerarse parte de la oferta académica de la ciudad de Bogotá y comparte el mismo público que las otras universidades de la capital.

31 Lista obtenida del buscador de programas del Ministerio de Educación de Colombia Disponible en: http://snies.mineducacion.gov.co/consultasnies/programa\# (consultada el 17 de enero de 2016).

32 Para la elaboración del presente análisis no se logró obtener los programas de la Universidad Santo Tomás, de la Universidad Cooperativa de Colombia ni de la Fundación Universitaria Los Libertadores, las cual también hacen parte de la lista de universidades de Bogotá cuyos programas de derecho cuentan con registro de alta calidad del Ministerio de Educación. 
que pretende estandarizar el análisis que se hace de los programas y poderlo replicar en otras ciudades y países ${ }^{33}$.

La siguiente tabla enlista, en orden alfabético, las universidades estudiadas, el carácter público o privado de las mismas y el número de programas analizado en cada una de ellas.

\begin{tabular}{|c|c|c|c|}
\hline & $\begin{array}{c}\text { NOMBRE DE LA } \\
\text { UNIVERSIDAD }\end{array}$ & $\begin{array}{c}\text { TIPO DE } \\
\text { UNIVERSIDAD }\end{array}$ & $\begin{array}{c}\text { NÚMERO DE } \\
\text { PROGRAMAS } \\
\text { ESTUDIADOS }\end{array}$ \\
\hline 1 & $\begin{array}{c}\text { Fundación Universidad de Bogotá } \\
\text { Jorge Tadeo Lozano }\end{array}$ & Privada & 2 \\
\hline 2 & Pontificia Universidad Javeriana & Privada & 3 \\
\hline 3 & Universidad de la Sabana & Privada & 3 \\
\hline 4 & Universidad de los Andes & Privada & 3 \\
\hline 5 & Universidad del Rosario & Privada & 2 \\
\hline 6 & Universidad Externado & Privada & 2 \\
\hline 7 & Universidad Libre & Privada & 3 \\
\hline 8 & Universidad Militar Nueva Granada & Pública & 2 \\
\hline 9 & Universidad Nacional de Colombia & Pública & 2 \\
\hline 10 & Universidad Sergio Arboleda & Privada & 3 \\
\hline
\end{tabular}

Si bien se trató de recaudar información suficientemente comparable, hay aspectos diferentes a tener en cuenta. Por ejemplo, algunas universidades tienen un sistema de libertad de cátedra absoluto en el que los profesores pueden elegir por completo el contenido del curso que van a dictar, mientras que en otras universidades hay un contenido programático esencial obligatorio que deben seguir los profesores. Además, no todos los programas tienen el mismo nivel de detalle y a veces se complementan con "planeadores" semanales con bibliografía y temas más detallados. Esta diferencia no siempre es fácil de establecer, pues el programa rara vez es claro en este sentido. Adicionalmente, no todas las universidades tienen el mismo número de asignaturas relacionadas con el DI y a veces la asignatura analizada es obligatoria y otras electiva. Igualmente, el DI no solo hace parte de la carrera de derecho, sino también puede ser parte de otras carreras, como Relaciones Internacionales ${ }^{34}$.

Hacer esta elección, que busca, como ya se dijo, obtener unos primeros resultados que permitan tener unas bases para enriquecer y profundizar la discusión en el futuro, tiene debilidades importantes. Elegir una ciudad capital

33 Véase Modelo de encuesta realizado en Anexo.

34 La mayoría de programas de DI analizados eran cursos dictados para la carrera de derecho, pero uno de ellos era un programa de DI de un curso dictado por un profesor de la facultad de derecho para una carrera de política y relaciones internacionales. 
y un tipo de universidades con clasificación similar busca obtener resultados comparables entre sí, pero esta selección restringida de universidades que dan acceso a una educación más privilegiada en contextos caracterizados por una profunda desigualdad educativa, económica y social, sin duda genera interrogantes como los siguientes: ¿qué tan replicables serán estos resultados? ¿Qué tan representativas de la educación del DI en Bogotá (y eventualmente Colombia) son estas universidades? ¿Qué obtenemos estudiando las "mejores" o la "élite educativa"? ¿Qué mide concretamente ese certificado de alta calidad del Ministerio (y todas las críticas que cualquier ranking y medición tiene consigo)? A pesar de estas dificultades, esta primera muestra busca ser lo más similar posible para poder evaluar qué tan parecidos o diferentes son los resultados en estos casos y probar el tipo de preguntas y encuesta realizada.

\section{ASPECTOS EVALUADOS}

Si bien la encuesta aplicada a los programas aborda numerosos temas ${ }^{35}$, en esta ocasión decidimos centrarnos en tres aspectos principales: i) objetivos y competencias buscadas (¿qué se persigue con el curso?, ¿qué se espera de los estudiantes al finalizar el mismo?), ii) contenido temático o programático (¿cuáles son los principales temas del DI que se enseñan?), y iii) bibliografía (¿qué bibliografía se selecciona -de dónde proviene, en qué idioma se propone, a qué orientación teórica pertenece, a qué periodo corresponde, etc.-?). Dentro de otros temas que queremos analizar en investigaciones futuras está particularmente el de indagar sobre las metodologías utilizadas y propuestas en los programas, relacionándolo con la manera que se considera más adecuada de enseñar el DI y con el tipo de relación y expectativa que se tiene de la interacción con los estudiantes.

Los tres aspectos que elegimos para analizar en esta ocasión nos permiten problematizar la creación de silencios y vacíos en la educación del DI, es decir, identificar la creación de epistemologías de ignorancia analizando, por ejemplo, si el DI se entiende como un concepto dado que se debe transmitir y aprender, si incluye bibliografía y contenidos tradicionales, críticos, interdisciplinares, locales, regionales, etc. El análisis más detenido de la agnotología a partir de los resultados de los tres aspectos priorizados se encuentra en la sección 5 de este artículo.

En las siguientes subsecciones se resumen los principales resultados encontrados en cada uno de los puntos mencionados. Teniendo en cuenta la política de confidencialidad acordada con los pares que nos compartieron sus programas, no se mencionan casos concretos o nombres de profesores y/o universidades. Nuestro interés, más que poner en evidencia los vacíos o fortalezas de ciertos programas con nombre propio, es que algunos cues-

Véase Encuesta en anexo. 
tionamientos y aspectos que se destacan en esta reflexión puedan servir para que cada uno, si así lo quiere y lo considera útil, se sirva de ellos en el mejoramiento de sus propios programas, y a la vez nos pueda servir de base para discusiones y propuestas futuras.

\subsection{Objetivos y competencias esperadas}

En este aspecto se evidencian algunas dificultades de comparación entre los programas. Algunos desarrollan en detalle los objetivos generales y específicos del curso y las competencias que se busca que el estudiante desarrolle, pero otros incluyen unas pocas líneas escuetas, y algunos incluso no hacen mención a ninguno de estos aspectos ${ }^{36}$.

A pesar de estas diferencias, de manera general parece evidente que todos los programas buscan familiarizar al estudiante con el DI. En general las clases de DI (y en particular las de DI público, pero en gran medida también las clases con alguna especialidad, como DI económico, privado o derechos humanos) fungen como una "Introducción al DI" en la que se busca presentar las particularidades del DI y diferenciarlo del derecho interno que ocupa la mayoría de la carrera. En este sentido, y como se ve con más claridad en los contenidos temáticos, se percibe que una de las principales metas buscadas en estos cursos es enseñar conceptos, lenguaje y tecnicismos propios del DI.

Si bien esto explica que sea común encontrar una lista de temas básicos muy similares entre cursos, incluso entre cursos con orientaciones teóricas diversas, resulta interesante que en la presentación del curso y los objetivos y competencias en él establecidos pocas veces se problematiza el DI. En general se hace énfasis en la necesidad de "aprender", "comprender", "identificar", "aplicar" unos conceptos técnicos específicos, cuyo contenido concreto y correcto abordará el curso. Así, más de la mitad de los programas (14) usan una redacción neutra respecto de los conceptos objeto de estudio y sobre el DI mismo (se estudiará cuál es "el" funcionamiento del DI, "cuáles son" los derechos y obligaciones que tiene un Estado en DI, cómo "la comunidad internacional concibe" las relaciones, cómo se forma el DI, etc.). En cambio, muy pocos (4) procuran matizar la universalidad de los contenidos diciendo que se presentarán "algunas discusiones" sobre cómo se concibe el DI, diciendo que el DI es variable, un producto histórico, que depende del contexto, etc.

Adicionalmente, casi la mitad de los programas (9) enfatizan que uno de sus objetivos importantes es proporcionar herramientas prácticas para que el estudiante pueda aplicar en la vida profesional esos conocimientos y resolver problemas concretos (con particular interés en el litigio). Pero solo 6 de ellos hacen alguna mención a que los cursos buscan desarrollar capacidades críticas y/o creativas por parte de los estudiantes.

36 Siete programas no incluyen los objetivos y/o las competencias esperadas. 
Finalmente, es de notar que en 6 programas el tema local/regional es abordado en los objetivos y competencias esperadas. La relación con Colombia se hace la mayoría de las veces para ver cómo se relaciona con la legislación nacional existente, y la relación con la región se circunscribe casi por completo a aprender los derechos y obligaciones de Colombia y mencionar las organizaciones regionales más importantes (el Sistema Interamericano de Derechos Humanos en clases de DI público o de derechos humanos, y organizaciones como la Comunidad Andina de Naciones y el Mercosur en clases de DI económico).

\subsection{Contenidos temáticos o programáticos}

En el contenido temático de los cursos se refuerza esa percepción de cursos introductorios que buscan dar a conocer conceptos básicos y un lenguaje técnico de DI. La inmensa mayoría de programas se dividen en módulos que abordan los temas más tradicionales, como los que se encuentran en el índice de un manual general de la materia. Así, con excepción de ciertos cursos de profundización o que tienen como prerrequisito una clase introductoria al DI, todos los demás programas (19) incluyen módulos sobre sujetos y/o fuentes del DI. De 17 programas de DI público o DI general, 11 incluyen de manera generalizada módulos sobre responsabilidad internacional, 10 sobre temas afines a la solución pacífica de controversias (la mayoría dedicando una o varias clases a los mecanismos jurisdiccionales, algunos menos incluyendo también mecanismos no jurisdiccionales), 9 sobre la protección internacional a la persona humana (en general derecho internacional humanitario, derecho internacional de los derechos humanos y derecho penal internacional) y 5 el uso de la fuerza.

Ahora bien, el carácter tradicional de los temas no significa que su análisis y discusión en clase sea también tradicional o clásico. Siendo clases introductorias resulta sensato que se discutan y estudien los principales temas del DI sobre los que se sigue escribiendo y debatiendo hoy en día. Los objetivos del curso y la bibliografía que el profesor propone pueden dar luces adicionales sobre qué tipo de posición se les da a esos temas en el curso, pues muchas veces precisamente para, por ejemplo, incluir críticas a la clasificación de fuentes o sujetos, resulta indispensable conocer las posiciones doctrinales y normativas que se critican.

Algo similar sucede cuando examinamos los programas que incluyen dentro de sus temas de estudio aspectos históricos y referencias locales y regionales en los programas propuestos. Por un lado. Vemos que 8 programas hacen referencia a la historia del DI, lo cual es un número nada despreciable. Pero más de la mitad de ellos (5) utilizan un lenguaje o redacción en los módulos según los cuales parecen presentar una perspectiva histórica que se considera uniforme y verdadera ("la" historia del DI, "el" desarrollo, "la evolución" 
del DI) y muchas veces eurocéntrica. Tan solo 3 presentan el estudio de la historia como un tema con cuestionamientos, ya sea sobre sus "evoluciones", la globalidad con que se "describe" habitualmente el DI o los paradigmas con los que se le presenta ${ }^{37}$.

Por otro lado, solo 6 programas incluyen referencias concretas en sus temas a lo local (Colombia) y 7 a lo regional (Latinoamérica). Sin embargo, casi siempre se limitan a estudiar la relación del DI con el derecho interno y/o a determinar qué derechos y obligaciones tiene Colombia en el DI (generalmente estudiando la normativa específica del área de estudio y el Sistema Interamericano de Derechos Humanos). Aunque escasos, es interesante señalar que 2 programas hacen un esfuerzo por relacionar el curso con problemáticas locales precisas (en particular con el conflicto armado colombiano), 3 por analizar aspectos más amplios de la relación entre el DI y Latinoamérica y/o su integración, y 1 propone estudiar la normativa interna de otros países de la región.

Finalmente, es de destacar que pocos programas dejan ver en su contenido temático un interés directo por ofrecer reflexiones interdisciplinares. Sin tener en cuenta las menciones a la historia del DI, solo 3 programas incluyen de manera explícita clases o módulos en los que se discuten o leen temas de otras disciplinas (en particular sobre la relación del derecho y la política, las relaciones internacionales, la antropología o la economía).

\subsection{Bibliografía}

Revisar la bibliografía que se incluye en los programas de clase supone preguntar por el origen geográfico de la bibliografía (¿tiene predominancia de una región?, ¿se incluyen autores locales y/o regionales?, etc.), el idioma de la mayoría de referencias sugeridas, si se pueden detectar una o varias corrientes teóricas incluidas y si alguna es dominante y, finalmente, a qué periodos temporales corresponde la bibliografía asignada. Estas preguntas buscan complementar algunos de los aspectos que hemos analizado en los puntos anteriores, pero no se debe olvidar que, como en esos mismos puntos, la mayoría de resultados que obtenemos son parciales. Por ejemplo, el origen de la literatura puede por un lado indicar interés en lo local y en lo regional y, por otro lado, el nivel de la influencia extranjera europea o angloestadounidense. Pero esto no revela necesariamente la tendencia teórica del curso (muchas veces la literatura nacional o regional es profundamente eurocéntrica o estadounicéntrica mientras que la proveniente de Europa o Estados Unidos puede ser mucho más crítica y preocupada por el contexto).

37 Es interesante señalar que esta presentación de la historia con matices se encuentra en un programa en el que los objetivos parecían ajenos a esas discusiones. 
Esto sucede también al examinar el idioma en que se encuentra la bibliografía del curso. Si bien podría pensarse que tiene sentido privilegiar el español en un curso que quiere destacar la relación e interacción con lo local, los debates propios de su contexto regional e incluso del Sur Global, o seguir una tendencia más cercana al movimiento TwAIL, en realidad vemos que la mayoría de esa literatura (aun proveniente de autores latinoamericanos) se produce en inglés. En este sentido, podemos encontrar cursos que utilizan textos en inglés y que contienen debates más críticos, así como cursos más eurocéntricos y estadounicéntricos que privilegian los textos en español. Por otro lado, el idioma en un contexto de educación tan desigual como el colombiano también puede ser un elemento de discriminación o inclusión. Si bien es creciente la tendencia a que las universidades incluyan en su oferta de cursos de pregrado (y en especial los relacionados con el DI) algunos cursos dictados enteramente en inglés, sigue siendo relativamente poca y privilegiada la población de estudiantes que pueden acceder a ellos. En este sentido, el idioma en que se presenta la bibliografía (y finalmente en el que decide publicarse) es un reto con consecuencias significativas (políticas y educativas, relacionadas con el énfasis teórico que se le quiere dar al curso y el público al que se quiere dirigir el mismo).

Al desglosar estos aspectos, el análisis de la bibliografía conduce a los siguientes resultados ${ }^{38}$.

Respecto al origen geográfico de la bibliografía doctrinal, en 15 programas la mayoría (o casi la mayoría) de textos son de origen europeo, 12 de origen nacional y 4 de Estados Unidos ${ }^{39}$. Por otro lado, 4 programas no incluyen ninguna referencia bibliográfica colombiana (o solo algunas normas, como la Constitución Política), 16 no incluyen ninguna referencia de doctrina latinoamericana (o bien incluyen solamente instrumentos o jurisprudencia del Sistema Interamericano de Derechos Humanos) y solo 2 incluyen algunas referencias de doctrinantes de otras regiones del mundo (además de colombianos, latinoamericanos, europeos o estadounidenses). Un programa propone solo bibliografía de origen europeo, otro hace lo mismo con bibliografía de Estados Unidos y la de otro más es una combinación de bibliografía europea y estadounidense.

Ahora bien, la literatura nacional incluida está principalmente compuesta por manuales o libros que siguen una tendencia clásica (no crítica) vinculada a la relación del DI con el derecho interno. La mayoría de referencias en

38 Téngase en cuenta que 1 de los programas revisados no tiene bibliografía y 1 no incluye fechas en sus referencias.

39 Hay casos en que no había una mayoría absoluta sino, por ejemplo, la misma cantidad de textos europeos y nacionales (exactamente el mismo número de lecturas o muy similar). En esos casos se sumaron los programas tanto a la lista de mayoría europea como a la de mayoría nacional. Esto explica que la suma de todos los programas en esta parte sea mayor a 24 programas. 
todos los idiomas son manuales o textos de DI generales de corte clásico. Los pocos autores de corrientes alternativas (críticas, TWAIL, marxistas u otros) que se incluyen en las bibliografías son de origen extranjero y de orígenes diversos, pero no de origen latinoamericano o nacional. Salvo pocos textos traducidos, la mayoría de estos autores se proponen en inglés.

En cuanto al idioma, la gran mayoría de programas proponen textos en español (16 programas) y algunos incluso solo incluyen bibliografía en este idioma (4 programas). Pero, como se mencionó anteriormente, hay un auge (al menos en este tipo de universidades) en cuanto a la implementación de cursos en inglés ${ }^{40}$, lo cual incrementa lógicamente la bibliografía en ese idioma. En este sentido, 16 programas contienen algún texto en inglés y 8 tienen la mayoría de los textos de su bibliografía en ese idioma, de los cuales 6 corresponden a clases dictadas enteramente en inglés.

Ahora bien, aunque hemos dicho arriba que una de las razones que pueden explicar la mayor presencia de textos en español corresponde a limitaciones lingüísticas de muchos estudiantes (y no siempre a un alineamiento teórico del profesor o profesora con los autores o los textos), debido a que preferir textos en inglés puede traducirse en un elemento discriminatorio en el contexto nacional, esto se ve confrontado con la sorprendente presencia de textos en francés: 16 programas incluyen algún texto en francés, y siempre se trata de manuales generales de corte clásico. Hay incluso 4 programas en los que no se incluye ningún texto en inglés y sin embargo sí se incluyen textos en francés. La presencia recurrente del francés parece evidenciar una fuerte influencia de la academia francesa en varios de los internacionalistas colombianos. Deja ver también que las razones por las que no se incluyen discusiones y críticas provenientes de corrientes teóricas diversas no solo corresponden a problemas de acceso al idioma por parte de los estudiantes, sino a decisiones voluntarias (probablemente basadas en afiliaciones, conocimiento y aproximaciones al DI) por parte de los profesores y profesoras. De hecho, de los 6 programas de clases dictadas enteramente en inglés, solo 1 incluye bibliografía de regiones y corrientes diversas (incluyendo la crítica).

Adicionalmente 12 programas incluyen jurisprudencia internacional como parte importante de su bibliografía de análisis. La mayoría proviene de la Corte Internacional de Justicia, seguida de la Corte Interamericana de Derechos Humanos y de contados casos de otros tribunales judiciales o arbitrales internacionales o regionales. Finalmente, en cuanto a los periodos temporales

40 Probablemente debido a que, en la evaluación de los "Lineamientos para la acreditación de programas de pregrado" (2013) del Consejo Nacional de Acreditación para otorgar la acreditación de alta calidad, se incluye dentro de los factores académicos de la integralidad del currículo un énfasis en "estrategias efectivas" para desarrollar "conocimientos, capacidades y habilidades comunicativas en un segundo idioma extranjero" (art. 5.4, característica 16, lit. J). Disponible en: http://www.cna.gov.co/1741/articles-186359_pregrado_2013.pdf 
de la bibliografía, es evidente que la gran mayoría de la doctrina propuesta es del siglo xxI. En 19 programas la doctrina del siglo xxI es mayoritaria y 7 de ellos solo incluyen lecturas de este periodo. La mayor diversidad bibliográfica deriva de la jurisprudencia, la cual, puesto que proviene a menudo de la Corte Internacional de Justicia, es esencialmente de la segunda mitad del siglo xx y del siglo xxI. Solo 4 programas incluyen doctrina de la primera mitad del siglo xx o de periodos anteriores, y curiosamente 2 programas no incluyen nada de doctrina del siglo XXI sino solamente de finales del siglo Xx (años 1980 y 1990).

\section{CREACIÓN DE VACÍOS Y EXPLICACIONES POSIBLES}

A partir de la información arriba presentada, en esta sección queremos reflexionar sobre la creación activa de vacíos y lagunas en la enseñanza del DI, creando epistemologías de ignorancia, lo cual se evidencia, entre otras, en la invisibilización de las aproximaciones críticas en la educación del DI en las universidades en Bogotá. Es importante señalar nuevamente (ver la sección anterior) que una de las dificultades en la problematización que se busca hacer es que estamos adelantando únicamente un análisis documental, y es posible que las dinámicas, las discusiones o la existencia de otros posibles currículos (ocultos o silenciados) de las clases sean muy diferentes de lo que reflejan los programas que analizamos.

Como se señaló en el diagnóstico, es interesante ver que existe una aproximación mayoritaria en los programas de DI de las universidades de Bogotá que siguen un corte clásico ortodoxo eurocéntrico, lo que se evidencia en los objetivos, contenido y bibliografía de los programas analizados. En especial, en el análisis de los objetivos y competencias pudimos encontrar que el DI se presenta generalmente como algo dado, objetivo, que debe comprenderse y dominarse técnicamente ${ }^{41}$. Lo anterior se evidencia en el hecho de que, en la mayoría de programas analizados, se enfatiza en una enseñanza de los aspectos básicos y técnicos del DI que le permitirán al estudiante contar con unas herramientas prácticas para la vida profesional y que le permitirán resolver problemas técnicos, concretos. Sin embargo, esta aproximación crea unos vacíos o lagunas en aspectos importantes como los orígenes del DI, su pasado colonial, su instrumentalización como herramienta de opresión, su aplicación y pertinencia local/regional, entre otras.

En cuanto a los contenidos programáticos, encontramos que existe en los programas analizados una selección tradicional de temas que son propios de cursos introductorios al DI. A partir de este hallazgo decidimos contrastar los resultados del análisis de los contenidos programáticos con la bibliografía incluida con el fin de determinar si los temas presentados en los contenidos

Véase supra, punto 4.1 . 
programáticos eran complementados con el uso de material bibliográfico amplio que permitiera la problematización del DI o sugiriera perspectivas alternativas, críticas o locales/regionales. Sin embargo, al revisar la bibliografía encontramos una fuerte influencia de literatura de origen europeo clásico; en el caso de la doctrina nacional, encontramos que esta también sigue una tendencia tradicional, limitada al uso de manuales que se caracterizan por tener aproximaciones básicas al DI desde una óptica clásica.

De esta forma, el análisis de los contenidos programáticos de los programas nos permitió evidenciar una creación de vacíos y silencios en el estudio del DI, en tanto que no se advierte la promoción del estudio desde una perspectiva amplia, que le permita al estudiante estudiar el DI más allá de unos conceptos básicos y de una aproximación al DI como una disciplina dada, objetiva y beneficiosa para todos. Los silencios y vacíos encontrados en los contenidos programáticos también se reflejaron en la bibliografía usada por los profesores, con muy poca presencia de material bibliográfico que presente corrientes alternativas (incluyendo, pero sin limitarse, a la corriente crítica). La creación de estos vacíos y silencios limita la posibilidad de que el estudiante pueda aproximar el estudio del DI desde una óptica más amplia que le permitiría, entre otras, entenderlo como un producto histórico. Variable, que se percibe de diferentes formas dependiendo del contexto, y que es el resultado de relaciones de poder que se evidencian en las estructuras y el funcionamiento del DI.

Distintas razones pueden llevar a que exista una marcada tendencia eurocéntrica clásica en la enseñanza del DI en las universidades de Bogotá que genera silencios respecto a otras aproximaciones en la educación del DI. Una de las explicaciones posibles puede ser el desconocimiento de aproximaciones críticas con enfoque de género, raza, o desde una perspectiva geopolítica en relaciones centro-periferia como lo pueden ser las aproximaciones del Tercer Mundo al derecho internacional (TWAIL) por parte de los profesores que enseñamos DI en las universidades de Bogotá. Sin embargo, consideramos que esta explicación es la que posee menos fuerza argumentativa, teniendo en cuenta que es altamente probable que los profesores de DI nos hayamos encontrado en algún momento con la existencia de aproximaciones críticas al DI (así sea tangencialmente), ya sea durante nuestros estudios o durante la preparación de las clases.

Una segunda explicación a la que atribuimos la creación de vacíos y silencios corresponde al lugar geográfico donde se enseña, pues los procesos académicos son distintos en el centro que en la periferia y pueden afectar las decisiones que tome un profesor ${ }^{42}$. En este sentido, la creación de los silencios puede estar relacionada con la percepción de que la intervención en los 
debates propios del DI que tienen lugar en el centro únicamente puede darse desde la óptica clásica eurocéntrica. Así, por ejemplo, Arnulf Becker Lorca señala que "la disciplina del derecho internacional no ofrece a abogados internacionalistas situados en la periferia herramientas analíticas adecuadas para entender el significado y los usos del derecho internacional en su propio contexto" ${ }^{43}$. Por ello, la educación del DI con materiales clásicos puede ser vista como una forma adecuada para que los abogados en formación puedan tener unas herramientas conceptuales que les permitan intervenir en los debates sobre el DI en el centro ${ }^{44}$.

Una tercera explicación en la creación de estos silencios puede hallarse en el hecho de que Colombia sea un país periférico desde una perspectiva geopolítica y que tiene un pasado colonial, lo que puede generar apoyos inconscientes a teorías clásicas eurocéntricas del DI, apoyos derivados del monopolio del conocimiento auto-adjudicado por Occidente (Europa Occidental y Norteamérica) ${ }^{45}$, derivado de lo que Enrique Dussel llama el mito de la modernidad, el cual que creó un discurso de superioridad epistemológica del conocimiento y de la razón de Occidente ${ }^{46}$. Lo anterior puede generar un desinterés claro por parte de los profesores en la enseñanza del DI desde una perspectiva más amplia que no cree puntos ciegos.

Una cuarta explicación posible en la creación activa de estos vacíos y puntos ciegos por parte de los profesores de DI puede ser el gran peso que han tenido las corrientes teóricas mayoritarias (mainstream) del DI, que han marcado el norte de ciertas pautas teóricas y prácticas del DI a nivel mundial ${ }^{47}$. En este sentido es importante señalar que a menudo las teorías mainstream determinan los temas que las editoriales y revistas más prestigiosas quieren publicar, los debates hacia los que se inclinan los principales centros académicos y el hecho de que el inglés sea el idioma en que se deba publicar, lo que hace que finalmente ciertos productos resulten siendo más citados y mejor calificados en los sistemas de rankings (rankings que a su vez

43 BECKER LORCA. International Law in Latin America or Latin American International Law? , cit., 283.

44 EsQuirol. Legal Latin Americanism, cit., 145.

45 Sobre el efecto del pasado colonial en la psiquis de los sujetos de antiguas colonias véase Frantz Fanon, Black Skin White Masks (Pluto Press 2008); De Sousa Santos, B. A critique of Lazy Reason: Against the Waste of Experience. En WallersteIn, I. (ed.), The Modern WorldSystem in the Longue Dureé (Routledge, 2016) 165.

46 De acuerdo con Enrique Dussel, el mito de la modernidad inicia en 1492 con el momento en el cual Europa se reconoce como tal y asume una superioridad sobre las otras formas culturales otras. En este contexto, la racionalidad europea se convirtió en la medida de evaluación del resto de culturas no europeas. Véase Dussel, E. 1492 - El encubrimiento del otro: hacia el origen del mito de la Modernidad. Plural Editores y Facultad de Humanidades y Ciencias de la Educación - UMSA, 1994.

47 Es importante señalar que así como referirse a la academia colombiana o latinoamericana como una masa homogénea es simplista y reduccionista, lo es también hablar de manera generalizada de las academias europeas y estadounidenses y del uso del concepto de mainstream. 
miden principalmente esas mismas editoriales, revistas y esos determinados idiomas, etc.), alimentando así un complejo círculo vicioso ${ }^{48}$. Sin duda, estas presiones actuales por competir en un mundo académico cada vez más profesionalizado y calificado cuantitativamente ejercen presiones en la agenda de enseñanza e investigación de los profesores de DI, en tanto que existe una dinámica de búsqueda constante de reconocimiento y legitimidad por parte de los creadores del conocimiento. Esta búsqueda de reconocimiento y legitimidad puede verse reflejada en la aceptación y uso de ciertas fuentes académicas por sobre otras.

Sea este el momento de reiterar que es problemático inferir que una educación con enseñanza con posiciones críticas del DI sea necesariamente mejor que una educación clásica eurocéntrica. Sin embargo, y como ya lo hemos mencionado en este artículo, consideramos que el uso de aproximaciones distintas a las clásicas ortodoxas, como lo pueden ser las aproximaciones críticas en la enseñanza del DI, les darían herramientas adicionales a los estudiantes y futuros internacionalistas bogotanos para poder problematizar los orígenes del DI y el papel que este juega en las relaciones geopolíticas globales y en la continuación de la existencia de monopolios normativos o jurídicos ubicados en Europa Occidental y en Norteamérica ${ }^{49}$.

\section{CONCLUSIONES}

Este artículo presentó un diagnóstico inicial a partir del análisis de 24 programas de cursos de DI de 10 universidades bogotanas. Como lo resaltamos en la introducción, esta investigación es compleja y puede tener distintas fallas. Vacíos y en algunos casos juicios que descansan sobre un muestreo reducido y sobre nuestros propios sesgos. A pesar de dichas dificultades de este primer diagnóstico, es posible llegar a algunas conclusiones preliminares que pueden servir de punto de partida a futuros trabajos de investigación.

En este estudio preliminar demostramos que la forma actual de educación del DI en Bogotá se caracteriza por una línea eurocéntrica clásica, no interdisciplinaria y donde la relación de la educación del DI con las problemáticas locales es limitada. De esta forma, por medio de este diagnóstico inicial, donde se analizaron los objetivos y competencias buscadas, los contenidos temáticos o programáticos y la bibliografía de cada uno de los programas revisados, logramos evidenciar una constante creación de silencios y vacíos en torno a una problematización amplia del DI.

48 Justamente, en la bibliografía que acá utilizamos se puede ver que la mayoría de textos son en inglés, así provengan de autores latinoamericanos y/o de corrientes críticas.

49 Para más sobre la creación de Monopolios Normativos en el DI. Ver PAHuja, S. Decolonising International Law: Development, Economic Growth and the Politics of Universality. Cambridge University Press, 2011, 6, 34, 45. 
La creación de silencios limita la percepción y la problematización que puedan tener los estudiantes, y los internacionalistas en general, sobre el DI, incluyendo reflexiones sobre su origen y su relación con los proyectos coloniales e imperialistas. Asimismo, reduce las posibilidades de cuestionar la presentación del DI como algo dado, objetivo y beneficioso para todos los actores; así como el papel que este juega en las relaciones geopolíticas globales y en la continuación de la existencia de situaciones de subordinación económica, política y epistemológica. Teniendo presente que este es un diagnóstico inicial, nos aventuramos a señalar cuatro posibles explicaciones de la creación de estas epistemologías de ignorancia en la educación del DI en Bogotá, a saber: el desconocimiento del docente; la ubicación geográfica del lugar donde se enseña; el pasado colonial de Colombia, y el peso de las corrientes mainstream en la naciente académica jurídica bogotana.

Consideramos que incluir en la enseñanza posiciones más amplias y variadas, como lo pueden ser las aproximaciones críticas al DI con enfoque de género, raza o TWAIL, da herramientas adicionales para incentivar el cuestionamiento de supuestos dados del DI. También otorga herramientas para cuestionar si su estudio requiere de énfasis en necesidades más locales y regionales, en cuestionamientos sobre su historia, localización geopolítica, etc.

Finalizamos invitando a nuestros pares a hacer parte de la problematización y discusión acá iniciada. Más que exponer una conclusión, queremos llamar a que se fortalezca el diálogo académico entre pares con realidades y necesidades similares, a que pensemos juntos nuevas propuestas adaptadas y pensadas en nuestro contexto, a debatir si este marco teórico es adecuado o si necesitamos también pensar en nuevas propuestas teóricas que den cuenta de nuestras carencias y destaquen nuestras virtudes, y, claro, a complementar (y criticar) este primer diagnóstico, sin duda incompleto.

\section{REFERENCIAS}

\section{Artículos y capítulos de libro}

Becker LorcA, A. (2006) International Law in Latin America or Latin American International Law? Rise, Fall, and Retrieval of a Tradition of Legal Thinking and Political Imagination. 47 (1), Harvard International Law Journal 283.

BRigido, A. M. y Lista, C. A. (2006) La enseñanza jurídica y el proceso de evaluación para la selección de funcionarios del Poder Judicial. Academia. Revista sobre Enseñanza del Derecho. 4(8), 213-232.

De Sousa Santos, B. (2005). La Universidad en el siglo XXI. Para una reforma democrática y emancipadora de la Universidad. México: UnAm/CEIICH.

De Sousa Santos, B. (2016). A critique of Lazy Reason: Against the Waste of Experience. En Wallerstein, I. (ed.), The Modern World-System in the Longue Dureé. Routledge. 
Esquirol, J. L. (2013). Legal Latin Americanism. Yale Human Rights \& Development Law Journal. 145.

Fix-Fierro, H. y López Avellón, S. (2006). La educación jurídica en México. Un panorama general. En R. Pérez \& J. Torres (eds.), La formación jurídica en América Latina, tensiones e innovaciones en tiempos de la globalización. Bogotá: Universidad Externado de Colombia, 143-184.

Gathis, J. T. (2011). twall: A Brief History of its Origins, its Decentralized Network, and a Tentative Bibliography. Trade, Law and Development. Vol. 3, n. ${ }^{\circ}$ 1, 26-64.

Jefreme McGee, J.; Guinot, M. y Connor, T. (2013). Rediscovering Law students as citizens critical thinking and the public value of legal education. Alternative Law Journal. $38(2), 1-8$.

Kennedy, D[Avid]. (1985). International Legal Education. Harvard International Law Journal. 26(2), 361-384.

Kennedy, D[AVID]. (1999). The disciplines of International Law and Policy. Leiden Journal of International Law. 12 (1) 9-133.

Kennedy, D[uncan]. (1980). First Year Law Teaching as Political Action. Law and Social Problems. 1(47), 47-58.

Kennedy, D[uncan]. (1983). The Political Significance of the Structure of the Law School Curriculum. 14 Seton Hall L. Rev. 14(1), 1-16.

Kennedy, D[uncan]. (1986) Liberal Values in Legal Education, Nova LJ. 10, 603-617.

Kennedy, D[uncan]. (1995). Politicizing the classroom. Review of Law and Women Studies. 4, 81-88.

Kennedy, D[unCan]. ([1982] 1998) Legal Education as Training for Hierarchy. En KaIRYs, D. (ed.). The Politics of Law: A Progressive Critique. New York: Basic Books.

Koskenniemi, M. (2010). What is International Law For? En Evans, M. D. International Law. Oxford University Press.

Kunz, J. L. (1946). A Plea for More Study of International Law in American Law Schools, 40 (3) The American Journal of International Law 624.

Lista, C. A. (1999-2000). La construcción de la conciencia jurídica: los objetivos educativos y la formación del abogado. Anuario 5(3), 381-404.

Lista, C. A. (2007). Los programas de "Derecho y Desarrollo" y la reforma judicial en América Latina, Anuario 10(7), 747-766.

Martín Alcoff, L. (2007). Epistemologies of Ignorance Three Types. En Shannon Sullivan, S. y Racel, N. T. (eds.). Race and Epistemologies of Ignorance. State University of New York Press.

Mendieta, E. (2011). The Ethics of (Not) Knowing:The Care of Ethics and Knowledge Will Come of Its own Accord. En Isasi-Díaz, A. M. y Mendieta, E. Decolonizing Epistemologies: Latina/o Theology and Philosophy. Fordahm University Press. 
Miles, K. (2010). International Investment Law: Origins, Imperialism and Conceptualizing the Environment, 21(1). Colorado Journal of International Environmental Law and Policy 1.

Montoya, J. (2010). The Current State of Legal Education Reform in Latin America: A Critical Appraisal. Journal of Legal Education. 9(4), 545-566.

Peña GonZÁlez, C. (2000, May 24-27). Characteristics and challenges of Latin American legal education. Paper presented at the Conference of International Legal Educators, Florencia, Italia.

Pérez Perdomo, R. (2009). Desafíos de la educación jurídica latinoamericana en tiempos de globalización. El Otro Derecho, La educación legal y la garantía de los derechos en América Latina. 38. Bogotá: ILSA - Instituto Latinoamericano para una Sociedad y un Derecho Alternativos.

Prieto-Ríos, E. (2015). Neoliberal Market Rationality: The Driver of International Investment Law. 3 (1), Birkbeck Law Review 55.

Prieto-Ríos. E. y Koram, K. (2015). Decolonising Epistemologies, Politicising Rights: An Interview with Eduardo Mendieta. 3 (1), Birkbeck Law Review 13.

Quijano, A. (2000). Colonialidad del poder, eurocentrismo y America Latina. En Lander, E. (ed.). La colonialidad del saber: eurocentrismo y ciencias sociales, perspectivas latinoamericanas. FACES/UCV, UNESCO, IESALC.

Salamanca Ramírez, F. A. (2010). Educación legal en Colombia. Análisis cuantitativo desde una perspectiva histórica. En García Villegas, M. (ed.). Los abogados en Colombia. Bogotá: Universidad Nacional de Colombia.

Silva García, G. (2006). Prospectivas sobre la educación jurídica. En Pérez Perdomo, R. y Torres J., C. (eds.). La formación jurídica en América Latina. Bogotá: Universidad Externado de Colombia.

Singh Chimni, B. (2006). Third World Approaches to International Law: A Manifesto. International Community Law Review. Vol. 8, 3-27.

Sullivan, S. y Racel, N. T. (2007). Introduction. En Shannon Sullivan, S. y Racel, N. T. (eds.). Race and Epistemologies of Ignorance. State University of New York Press.

\section{Libros}

AnghIE, A. (2007). Imperialism, sovereignty, and the making of International Law. Cambridge: Cambridge University Press.

Dussel, E. (1994). 1492. El encubrimiento del otro: hacia el origen del mito de la Modernidad. Plural Editores y Facultad de Humanidades y Ciencias de la Educación - UMSA.

Eslava, L. (2016). Local Space, Global Life. Cambridge: Cambridge University Press.

FAnon, F. (2008). Black Skin White Masks. Pluto Press. 
Pahuja, S. (2011). Decolonising International Law: Development, Economic Growth and the Politics of Universality. Cambridge University Press.

Pérez Perdomo, R. (2006). La formación jurídica en América Latina, tensiones e innovaciones en tiempos de la globalización. Bogotá: Universidad Externado de Colombia, 2006.

\section{Material en línea}

Beckett, J. (2012). Critical International Legal Theory, Oxford Bibliographies Online: http://oxfordindex.oup.com/view/10.1093/obo/9780199796953-0007

Consejo Nacional da Acreditación: http://www.cna.gov.co/

Consejo Nacional de Acreditación (2013). Lineamientos para la acreditación de programas de pregrado. En: http://www.cna.gov.co/1741/articles-186359_pregrado_2013.pdf

Diccionario de la RAE, en: http://dle.rae.es/?id=Fy2OT7b

Ministerio de Educación de Colombia. Lista de programas de derecho con registro de alta calidad: http://snies.mineducacion.gov.co/consultasnies/programa\# Consultada el 17 de enero de 2016. 
ANEXO

MODELO DE ENCUESTA ELABORADO PARA ANÁLISIS

DE PROGRAMAS DE CURSOS DE DI

País

Ciudad

Nombre de la universidad

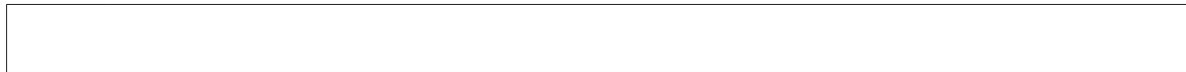

Tipo de universidad

Pública

Privada

$\square$ En ciudad capital

$\square$ En regiones

Otros:

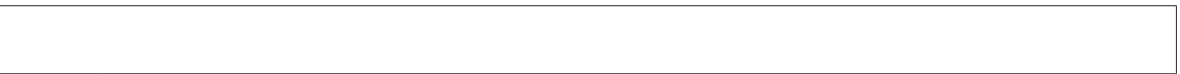

Nombre de la asignatura

Nombre del profesor

Año del curso

Duración (módulo, semestre, año...)

¿En qué facultad se incorpora la asignatura?

Derecho / Jurisprudencia

Relaciones Internacionales

Ciencia Política 
$\square$ Ciencias Sociales (no incluye Derecho)

$\square$ Ciencias Sociales/Políticas y Derecho

Otros:

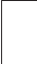

¿Dentro de qué área/departamento de la facultad se incorpora esta clase?

Departamento de Derecho

$\square$ Área Derecho Público

$\square$ Área Derecho Público

$\square$ Área Derecho Constitucional

Ciencia Política

$\square$ Relaciones Internacionales

$\square$ Estudios Internacionales

Otros:

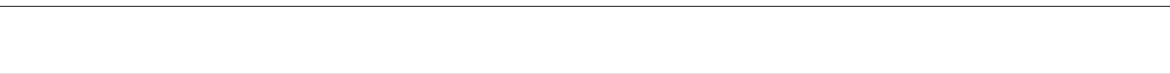

Intensidad horaria del curso (número de horas semanales)

Nivel

$\square$ Pregrado

$\square$ Posgrado

Semestre (si es anual haga la equivalencia y marque el primer semestre que corresponda. Ej.: curso en $2 .^{\circ}$ año: marcar $3 .^{\text {er }}$ semestre, suponiendo que dura los semestres $3 .^{\circ}$ y $4 .^{\circ}$ )

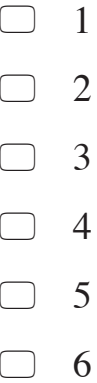




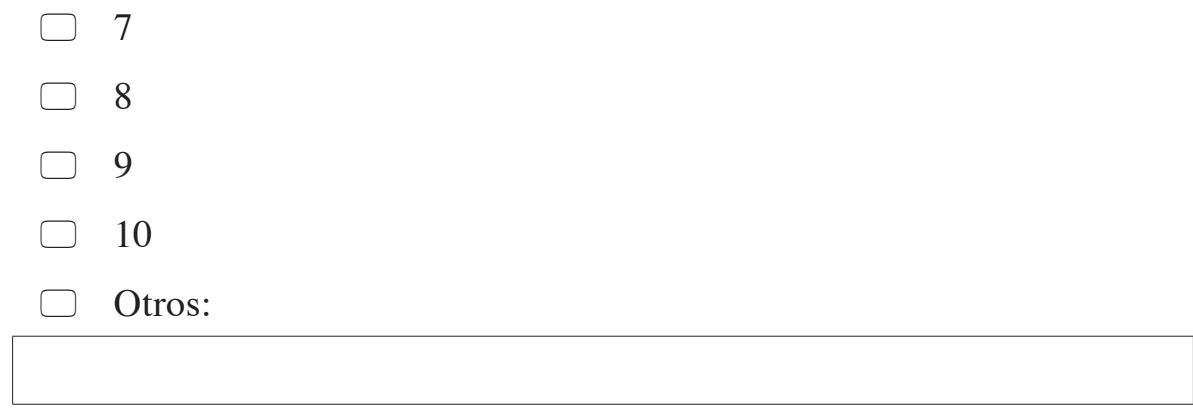

Tipo de asignatura

$\square$ Obligatoria

$\square$ Electiva

$\square$ Con prerrequisito

$\square$ Sin prerrequisito

$\square$ Es prerrequisito de otra clase

$\checkmark$ Cátedra

Taller/seminario

Otros:

¿Se dice cuál es la metodología que se va a emplear para desarrollar la clase?

$\square$ Sí, se desarrolla de forma clara

$\square$ No se dice nada

Algunos aspectos breves

¿Qué tipo(s) de metodología(s) se propone(n) para la clase? (pueden señalarse varias)

Cátedra magistral

Debates

$\square$ Cátedra activa

$\checkmark$ Seminario

$\square$ Taller

$\square$ Tribunal simulado (mootcourt) 
Aprendizaje colaborativo

No se precisa

Otros:

¿Se señalan metodologías específicas para actividades puntuales en clase?

Resolución de casos

$\checkmark$ Presentaciones/exposiciones de estudiantes (grupales o individuales)

$\square$ Trabajos de grupo

$\square$ Tribunal simulado (mootcourt)

Análisis de problemas

Análisis de textos

$\square$ Elaboración de videos o audios por parte de los estudiantes

Creación de blogs/foros/discusiones interactivas

$\square$ Investigación personal

$\square$ No se señalan

$\square$ Otros:

¿Se mencionan herramientas o ayudas pedagógicas adicionales para la clase?

Blogs/foros/discusiones interactivas...

Presentación y discusión de videos, películas, documentales o audios

Clickers

$\square$ Invitados, conferencistas, expertos

$\square$ No se mencionan

Otros:

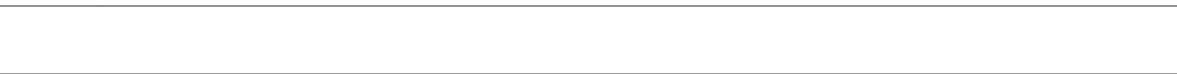

¿Se señalan herramientas para compartir información y documentos?

Grupo de correos 
$\square$ La universidad dispone de una plataforma de interacción virtual para compartir lecturas, hacer y colgar exámenes, colgar y acoger discusiones, etc.

Blog de la clase

$\square$ No se señalan

$\square$ Otros:

¿El programa especifica los objetivos teóricos, sustantivos y académicos del curso?

Sí

$\square$ No

Si sí, ¿cuáles son los objetivos?

¿Se posiciona teóricamente el curso?

Sí

No

Si sí, ¿cómo se posiciones teóricamente?

¿Se dice qué se espera del estudiante al finalizar el curso?

Sí

$\square$ No

Si sí, ¿qué se espera?

¿Cuáles son las formas de evaluación que emplea?

$\square$ Exámenes parciales

Exámenes acumulativos

Exámenes escritos en clase

Exámenes escritos fuera de clase 
$\square$ Exámenes orales

Exámenes de selección múltiple

$\square$ Evaluaciones individuales

$\square$ Evaluaciones en grupo

$\square$ Exposiciones

Resolución de casos

Quices/comprobaciones de lectura

$\square$ Análisis de problemas (PBL)

$\square$ Ensayos

Participación en clase

$\square$ Tribunal simulado

$\square$ Asistencia a clase

$\square$ Talleres y actividades adicionales

No se explica/detalla

$\square$ Otros:

¿Se evalúa usando una matriz de evaluación previamente definida?
Sí
$\square$ No
$\square$ Otros:

Si sí, ¿la matriz se incluye en el programa?

Sí

$\square$ No

¿Qué aspectos se dice que se evalúan?

Participación

Asistencia 
$\square$ Temas específicos

$\square$ Temas acumulativos

Análisis de problemas

Análisis crítico/personal

Trabajos en grupo

Aspectos formales

Expresión oral

Expresión escrita

$\square$ Investigación personal

$\square$ No se describe

Otros:

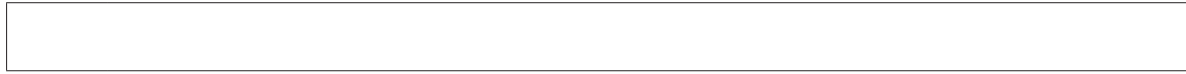

¿Número de pruebas/exámenes y porcentajes?

¿El curso se divide en módulos temáticos o cronológicos? ¿Cuáles son?

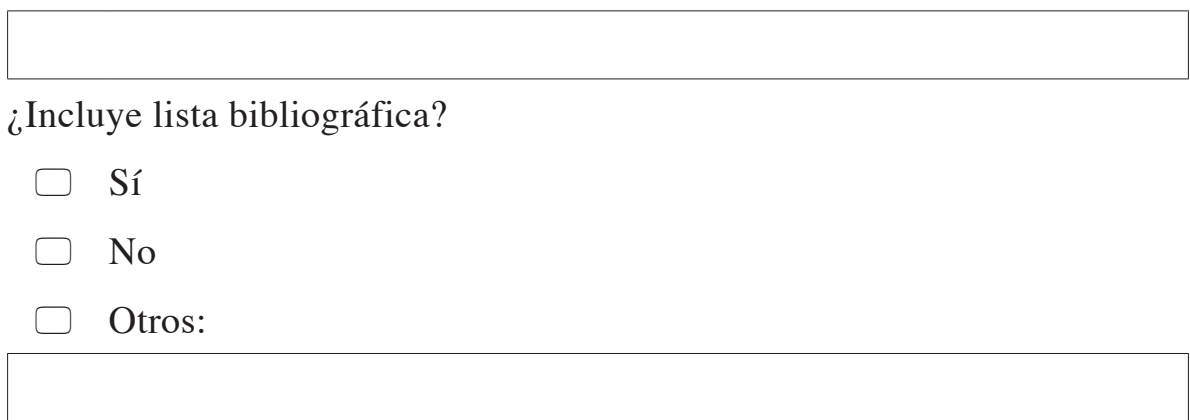

Si sí, ¿cómo se incluye?

General (básica/obligatoria y complementaria)

Por temas/módulos

$\square$ Por cada clase/día

Por actividad 


\section{Otros:}

¿Qué tipo de bibliografía se emplea?

$\square$ General de DI (manuales o cursos generales)

$\square$ Específica científica de DI (artículos científicos, libros especializados, sentencias o casos puntuales)

$\square$ Específica no científica relacionada con DI (artículos de prensa sobre tema de DI, documentos diplomáticos, películas, documentales, otros)

$\square$ De otras disciplinas (ciencia política, historia, derecho interno colombiano, sociología, relaciones internacionales, religión, etc.)

¿De qué origen(es) es la bibliografía?

$\square$ Nacional

$\square$ Latinoamericana

Estadounidense

$\square$ Europea

$\square$ Otros:

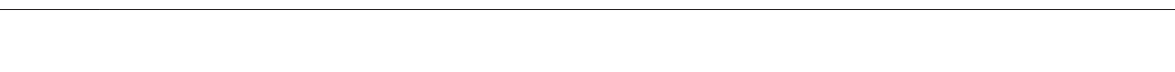

Si la bibliografía tiene varios orígenes, enumere la lista anterior de mayor a menor, siendo 1 la más utilizada y 5 la menos utilizada.

¿En qué idioma(s) está la bibliografía?

Español

Inglés

$\square$ Portugués

$\square$ Francés

Otros: 
Si está en varios idiomas, retome la lista anterior y enumérelos de mayor a menor, siendo 1 la más utilizada y 5 la menos utilizada.

¿De qué periodos es la bibliografía utilizada?

Siglo XXI

$\square$ 1980-1999

$\square$ 1945-1979

$1900-1944$

Siglo XIX

Anterior al siglo XIX

Otros:

Si proviene de varios periodos, enumérelos de mayor a menor, siendo 1 la más utilizada y 5 la menos utilizada.

¿Cómo se accede a la bibliografía?

El profesor la comparte en digital (e-mail, blog, etc.)

Se cuenta con plataforma institucional para compartir bibliografía

Los estudiantes deben conseguirla/investigarla

Se deja en una fotocopiadora

Se basa en un libro básico que se debe comprar/fotocopiar/descargar...

No se precisa en el programa

Se ponen enlaces (links) para descargar/leer en línea

$\square$ Otros: 
¿La clase maneja una aproximación interdisciplinaria al DI?

Sí

No

Si sí, ¿cuál? 